Erratum

\title{
Erratum to "Antiasthmatic Effects of Herbal Complex MA and Its Fermented Product MA128"
}

\author{
Dong-Seon Kim, ${ }^{1}$ Seung-Hyung Kim, ${ }^{2}$ Bok-Kyu Kim, ${ }^{2}$ Min Cheol Yang, ${ }^{1}$ and Jin Yeul Ma ${ }^{1}$ \\ ${ }^{1}$ Herbal Medicine Improvement Research Center, Korea Institute of Oriental Medicine, Daejeon 305-811, Republic of Korea \\ ${ }^{2}$ Institute of Traditional Medicine \& Bioscience, Daejeon University, Daejeon 300-716, Republic of Korea \\ Correspondence should be addressed to Jin Yeul Ma; jyma@kiom.re.kr
}

Received 5 December 2013; Accepted 18 December 2013; Published 30 January 2014

Copyright (c) 2014 Dong-Seon Kim et al. This is an open access article distributed under the Creative Commons Attribution License, which permits unrestricted use, distribution, and reproduction in any medium, provided the original work is properly cited.

In the whole paper, Lactobacillus acidophilus was incorrectly used. The correct name is Lactobacillus rhamnosus.

The authors apologize for this error. 


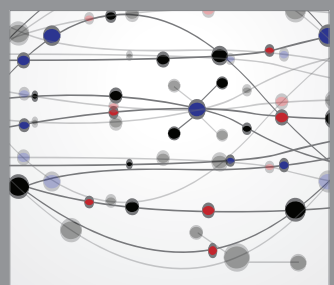

The Scientific World Journal
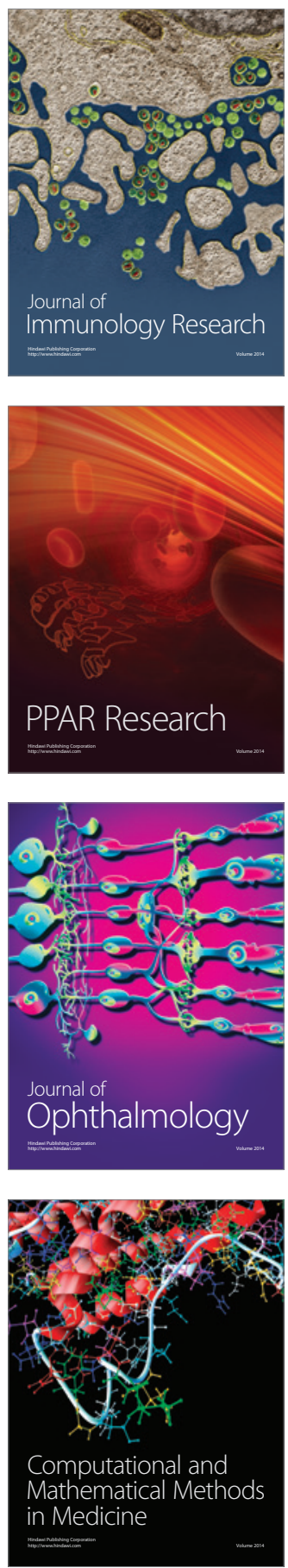

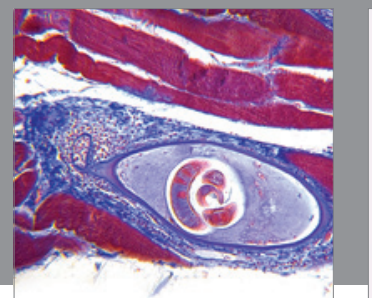

Gastroenterology

Research and Practice
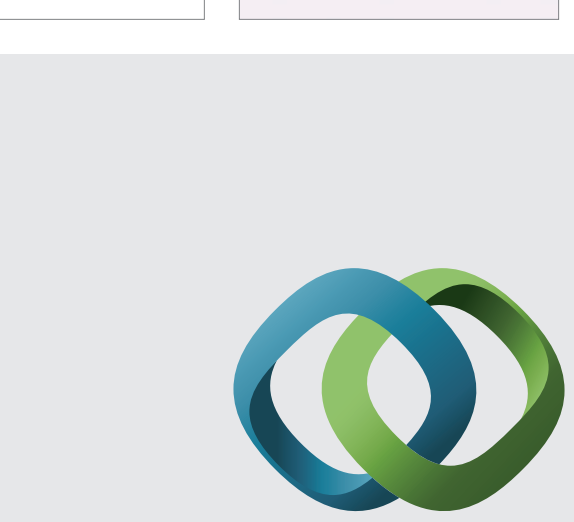

\section{Hindawi}

Submit your manuscripts at

http://www.hindawi.com
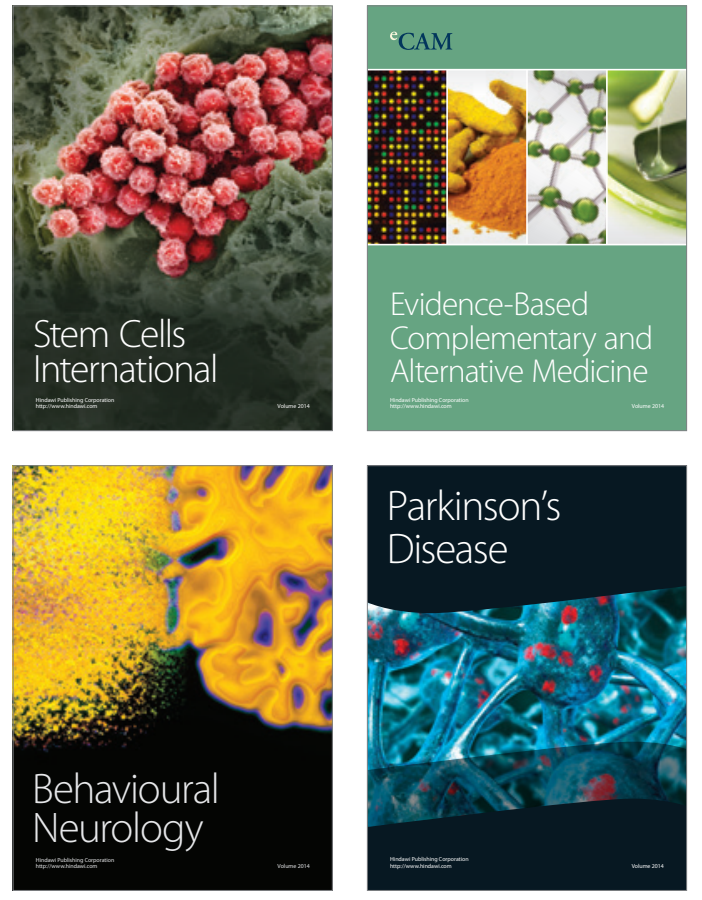
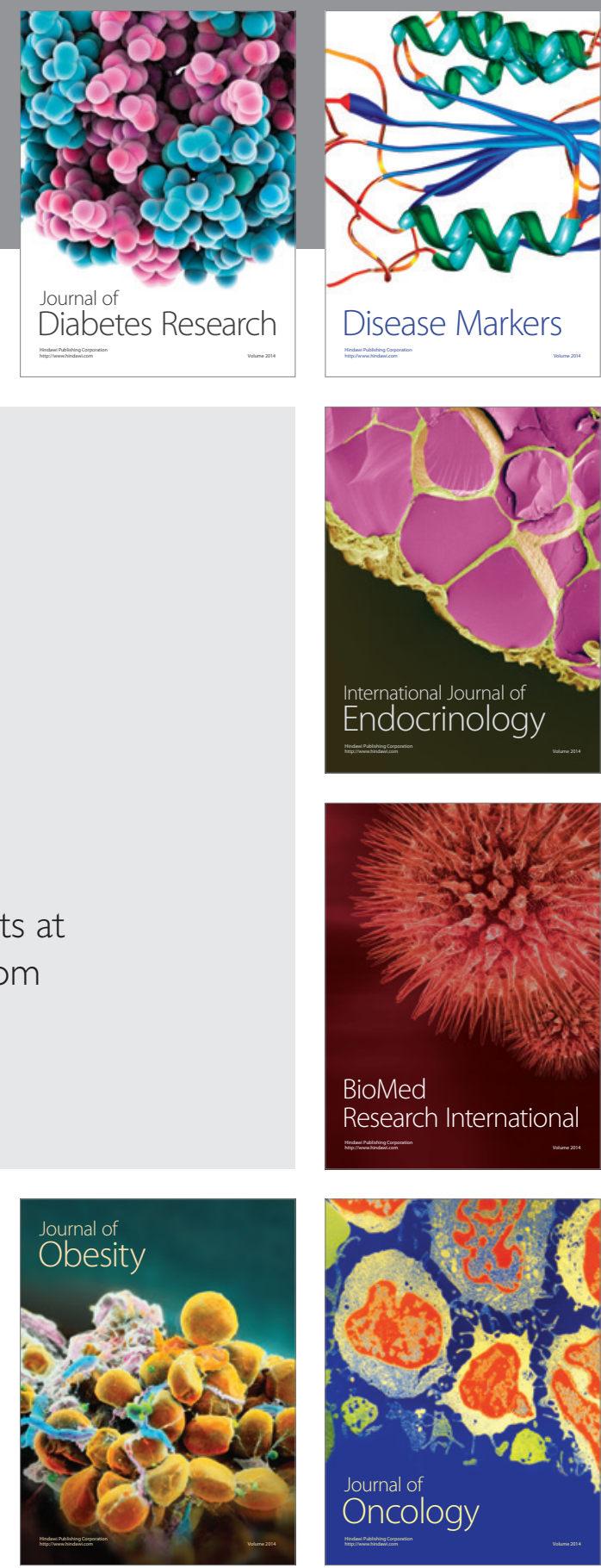

Disease Markers
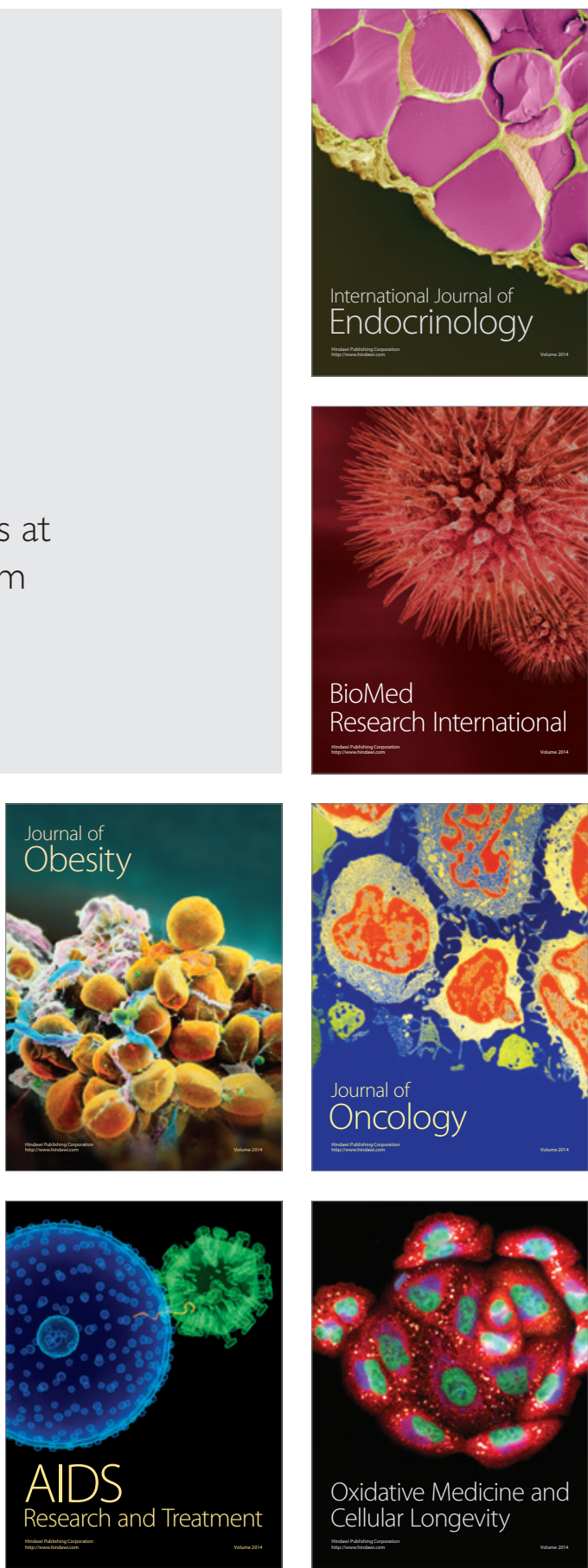